\title{
Exercise MRI highlights heterogeneity in cardiovascular mechanics among patients with Fontan circulation: proposed protocol for routine evaluation
}

\author{
Francisco Contijoch ${ }^{1,2}$, Bochao Li $^{1}$, Weiguang Yang ${ }^{3}$, Jose A. Silva-Sepulveda ${ }^{4}$, Irine Vodkin ${ }^{5}$, \\ Beth Printz $^{4}$, Vera Vavinskaya ${ }^{6}$, Sanjeet Hegde ${ }^{4}$, Alison Marsden ${ }^{3,7}$, Hannah El-Sabrout ${ }^{8}$, \\ Laith Alshawabkeh ${ }^{5}$, John W. Moore ${ }^{4}$, Howaida El-Said ${ }^{4}$
}

${ }^{1}$ Department of Bioengineering, ${ }^{2}$ Department of Radiology, UC San Diego, La Jolla CA, USA; ${ }^{3}$ Department of Pediatrics, Stanford University, Palo Alto, CA, USA; ${ }^{4}$ Department of Pediatric Cardiology, Rady Children's Hospital, San Diego, CA, USA; ${ }^{5}$ Department of Medicine, ${ }^{6}$ Department of Pathology, UC San Diego, La Jolla, CA, USA; ${ }^{7}$ Department of Bioengineering, Stanford University, Palo Alto, CA, USA; ${ }^{8}$ Department of Society and Genetics, UC Los Angeles, Los Angeles, CA, USA

Contributions: (I) Conception and design: H El-Said; (II) Administrative support: None; (III) Provision of study materials or patients: H El-Said, JA Silva-Sepulveda, B Printz; (IV) Collection and assembly of data: F Contijoch, B Li, JA Silva-Sepulveda, B Printz, I Vodkin, V Vavinskaya, H El-Said; (V) Data analysis and interpretation: F Contijoch, B Li, W Yang, JA Silva-Sepulveda, B Printz, I Vodkin, V Vavinskaya, A Marsden, H El-Said; (VI) Manuscript writing: All authors; (VII) Final approval of manuscript: All authors.

Correspondence to: Howaida El-Said, MD, PhD. Professor of Pediatric Cardiology, University of California San Diego, Director of Cardiac Cath Lab, Rady Children’s Hospital, San Diego, CA, USA. Email: hgelsaid@yahoo.com.

\begin{abstract}
Single ventricle physiology and palliation via the Fontan operation lead to a series of cardiovascular changes. In addition, organs such as the kidneys and liver have been shown to experience insults and subsequent injury. This has led to routine surveillance of patients. We present findings from a small cohort of patients that was deeply phenotyped to illustrate the need for comprehensive evaluation. A cohort of four Fontan patients with fairly high cardiovascular function was recruited 5-10 years postFontan. Patients underwent a rigorous clinical work-up after which a research MRI scan was performed during which (I) data were obtained during exercise to evaluate changes in stroke volume during supine exercise and (II) magnetic resonance angiograms with phase-contrast images were obtained for computational modeling of flows through the Fontan circulation at rest. Clinical measures were consistent with a fairly homogeneous high function cohort (peak oxygen consumption $>20 \mathrm{~mL} / \mathrm{kg} / \mathrm{min}$, robust response to exercise, peak ventilatory efficiency below levels associated with heart failure, MR-derived ejection fraction $>50 \%$ ). Liver evaluation did not reveal clear signs of cirrhosis or extensive fibrosis. However, we observed considerable variability (27-162\%) in the increase in stroke index with exercise $\left[100 \% \pm 64 \%\right.$ increase, $53.9 \pm 17.4 \mathrm{~mL} /$ beat $^{2}$ (rest), $101.1 \pm 20.7 \mathrm{~mL} /$ beat $\mathrm{m}^{2}$, (exercise)]. Computational flow modeling at rest in two patients also showed marked differences in flow distribution and shear stress. We report marked differences in both changes in stroke index during an exercise MRI protocol as well as computational flow patterns at rest suggesting different compensation strategies may be associated with high functioning Fontan patients. The observed heterogeneity illustrates the need for deep phenotyping to capture patient-specific adaptive mechanisms.
\end{abstract}

Keywords: Fontan; exercise; magnetic resonance imaging; flow modeling

Submitted Aug 23, 2019. Accepted for publication Sep 17, 2019.

doi: $10.21037 /$ jtd.2019.09.59

View this article at: http://dx.doi.org/10.21037/jtd.2019.09.59 


\section{Introduction}

Single ventricle physiology is complicated by a variety of challenges including an overworked ventricle, a potentially failing valve, a pulmonary bed that is either volume overloaded or underdeveloped, and brain that has experienced repetitive ischemic insults. Specifically, in addition to systolic dysfunction, the ventricle has been shown to have diastolic dysfunction (loss of relaxation) prior to systolic impairment (1). The atrioventricular valves can become regurgitant due to several mechanisms including annular dilation and abnormal chordae or papillary muscles (2). In addition, the dilated neoaortic root and neoaortic valve insufficiency are late complications after the Norwood operation that occurs after the Fontan operation (3).

The Fontan operation consists of directing vena caval flow into the pulmonary arteries, thereby bypassing the heart with the goals of eliminating cyanosis, reducing volume overload, and improving exercise tolerance (4). Since the Fontan palliation was first reported in 1971, many studies have looked at the associated physiology and outcomes. As a result, the procedure itself has been shown to limit exercise capacity, increase central venous pressure and decrease cardiac output compared to patients with normal cardiac physiology $(5,6)$. In addition, dormant embryonic venous vessels re-open connecting the highpressure Fontan circuit to the low pressure pulmonary venous circulation (VV collaterals) (7) in hopes of bypassing the congested route. This causes cyanosis which leads to embryonic arteries connecting the aorta to the lungs (AP collaterals) as a compensatory mechanism. Not only does this lead to volume overload the already struggling ventricle (elevating the diastolic pressure) but also causes volume overload in lungs which further exacerbates the problem.

The Fontan circulation is also hostile to other organs such as the kidney with incidence of postoperative acute renal failure in almost $40 \%$ (8) and $46 \%$ of adult patients experiencing chronic kidney disease (9). However, the liver is particularly susceptible due to prolonged elevation of hepatic venous pressure and low cardiac output causing hepatic congestion, hypoxia and decreased portal blood flow. As a result, pathological changes in the liver have been observed as early in 1983 first in a 15 -year-old girl 5 years after a modified Fontan operation for tricuspid atresia (10) and autopsy specimens showing liver fibrosis after Fontan (11) with a unique pattern of chronic liver injury (12). Given the number of questions and lack of answers in this population, the American Heart Association's 2019 guidelines have proposed surveillance testing for Fontan patients (13). Our group had developed a surveillance protocol in our institution that was implemented in 2015 (see Table 1). MRI liver elastography has emerged as the noninvasive technique to predict the degree of fibrosis in non-Fontan patients (14). However, hepatic venous congestion limits our ability to estimate liver fibrosis (15). Recent work has quantified fibrosis in the non-Fontan patient population via liver biopsy and MRI elastography (16) and our group has recently showed developed a Fontan-specific scoring system to quantify worsening liver stiffness and fibrosis with time (17).

One important question that remains unanswered in this population is whether liver fibrosis leads to decreased cardiovascular function. We present a unique observational case series in which four Fontan patients underwent a rigorous clinical work-up and an additional research MRI scan during which (I) an exercise MRI protocol was performed to evaluate changes in stroke volume during supine stepping exercise, (II) a MR angiogram with phasecontrast images was acquired to construct computational models of flows through the Fontan circuit, and (III) cardiac catheterizations and liver biopsies were performed to evaluate Fontan associated liver disease. Here, we present observations drawn from this deeply-phenotyped case series to illustrate the need for comprehensive assessment to evaluate patient-specific adaptive mechanisms.

\section{Methods}

\section{Patient population}

Four Fontan patients were prospectively recruited from Rady Children's Hospital San Diego between 8/2014 and $7 / 2018$. Clinical practice includes routine screening 5-10 years post-Fontan that includes a cardiac catheterization, trans-jugular liver biopsy, echocardiography, cardiopulmonary exercise testing (CPET), laboratory testing, and assessment of the liver stiffness by magnetic resonance elastography (MRE) and transient elastography. The 4 patients enrolled had routine tests performed within 6 months of enrolling in the study, did not have pacemakers, were recruited from the clinical practice, and consented to undergo a research MRI study. The research MRI study was performed at the University of California, San Diego and the institutional review boards at both institutions approved the study. 
Table 1 Fontan outpatient protocol for asymptomatic patients

\begin{tabular}{|c|c|c|c|}
\hline Examination & Frequency & Measurements & Referrals \\
\hline Routine evaluation & $\begin{array}{l}\text { Every } 2-3 \text { years } \\
\text { or PRN }\end{array}$ & $\begin{array}{l}\text { CBC w/diff, IgG, CMP, GGT, INR, BNP, uric acid, ferritin, iron } \\
\text { studies; serum cystatin C, UA; DEXA scan, TSH, PTH, and } \\
\text { vitamin D level; document hepatitis A and B immunity: Hep } \\
\text { B surface antibody and Hep A antibody. (Give vaccines if not } \\
\text { immune). Hep C screening for patient with a blood transfusion } \\
\text { before July } 1991\end{array}$ & $\begin{array}{l}\text { Endocrine; nephrology; } \\
\text { neurological/psychological; } \\
\text { nutrition; immunology as } \\
\text { needed }\end{array}$ \\
\hline \multirow[t]{2}{*}{$\begin{array}{l}5 \text { years } \\
\text { post-Fontan }\end{array}$} & Every 3 years & $\begin{array}{l}\text { MRI cardiac; MRI liver elastography (prefer) or US Fibroscan or } \\
\text { liver US; exercise testing }\end{array}$ & Hepatology \\
\hline & As needed & Cardiac catheteriation with liver biopsy & \\
\hline $\begin{array}{l}10 \text { years post- } \\
\text { Fontan }\end{array}$ & Every 10 years & Cardiac catheterization & \\
\hline
\end{tabular}

EKG, electrocardiogram; PRN, pro re nata (as needed); CBC, complete blood count; CMP, comprehensive metabolic panel; GGT, gamma-glutamyl transferase; INR, international normalized ratio; BNP, brain natriuretic peptide; UA, urinalysis; DEXA, dual-energy X-ray absorptiometry; TSH, thryoid-stimulating hormone; $\mathrm{PTH}$, parathyroid hormone; US, ultrasound; ACHD, adult congenital heart disease.

\section{Clinical assessment}

Cardiac catheterization, trans-jugular liver biopsy, hemodynamic measurements, clinical cardiac MRI, CPET, and laboratory studies were obtained as described by Silva Sepulveda et al., which developed a Fontan-specific modified Ishak Congestive Hepatic Fibrosis score (mICHF) (score 0-6) (17).

\section{Research cardiac MRI}

The research cardiac MRI was performed on a $1.5 \mathrm{~T}$ Excite HDx (GE Healthcare, Waukesha, WI) scanner. After acquisition of conventional long and short-axis ECGgated cine images and MR angiography, 2D phase contrast was performed to quantify flow through the superior vena cava, inferior vena cava, right and left pulmonary arteries, ascending, and descending aorta. Thirty images were acquired across the cardiac cycle with voxel size $=1.1-1.4 \mathrm{~mm}$ in plane, slice thickness $=5 \mathrm{~mm}, \mathrm{TE}=3.0-3.5 \mathrm{~ms}$, $\mathrm{TR}=5.4-8.1 \mathrm{~ms}$, flip angle $=20-25$ degrees, and field of view $=280-350 \mathrm{~mm}$. Patients exercised with an MRIcompatible pedal ergometer set at 20-watt output (Lode, Groningen, Netherlands). 2D phase contrast images of the ascending aorta were obtained after 3 -minute periods of exercise during a single breathhold with an associated brief cessation $(\sim 10$ seconds) of exercise. Patients performed $4 \pm 1.4$ (range, 3-6) periods of exercise. Flow through the ascending aorta was quantified using Cardiac MRI Suite (Arterys, San Francisco, CA, USA).

\section{Computational flow modeling}

Patient-specific flow models were created from shortaxis images with flow derived from PC MRI images using the open source package Simvascular (18-21). MRIderived inflow waveforms were prescribed at the inlets of the superior vena cava and inferior vena cava with a respiratory model (22). Total resistance of the Windkessel model was chosen to match Fontan pressures measured by catheterization and pulmonary flow distribution measured by phase contrast-MRI (21-23). After the velocity field for the Fontan circuit was obtained from flow simulations, Lagrangian particle tracking was used to quantify the hepatic flow distribution (24).

\section{Statistical analysis}

Continuous data was summarized as mean with standard deviation when normally distributed or as median with range for data with skewed distribution. Data was summarized as numbers with percentages for discrete data. Two-tailed $t$-tests were used for continuous data (paired if appropriate). A P value of less than 0.05 was considered statistically significant. 
Table 2 Subject demographics and pertinent surgical and clinical information

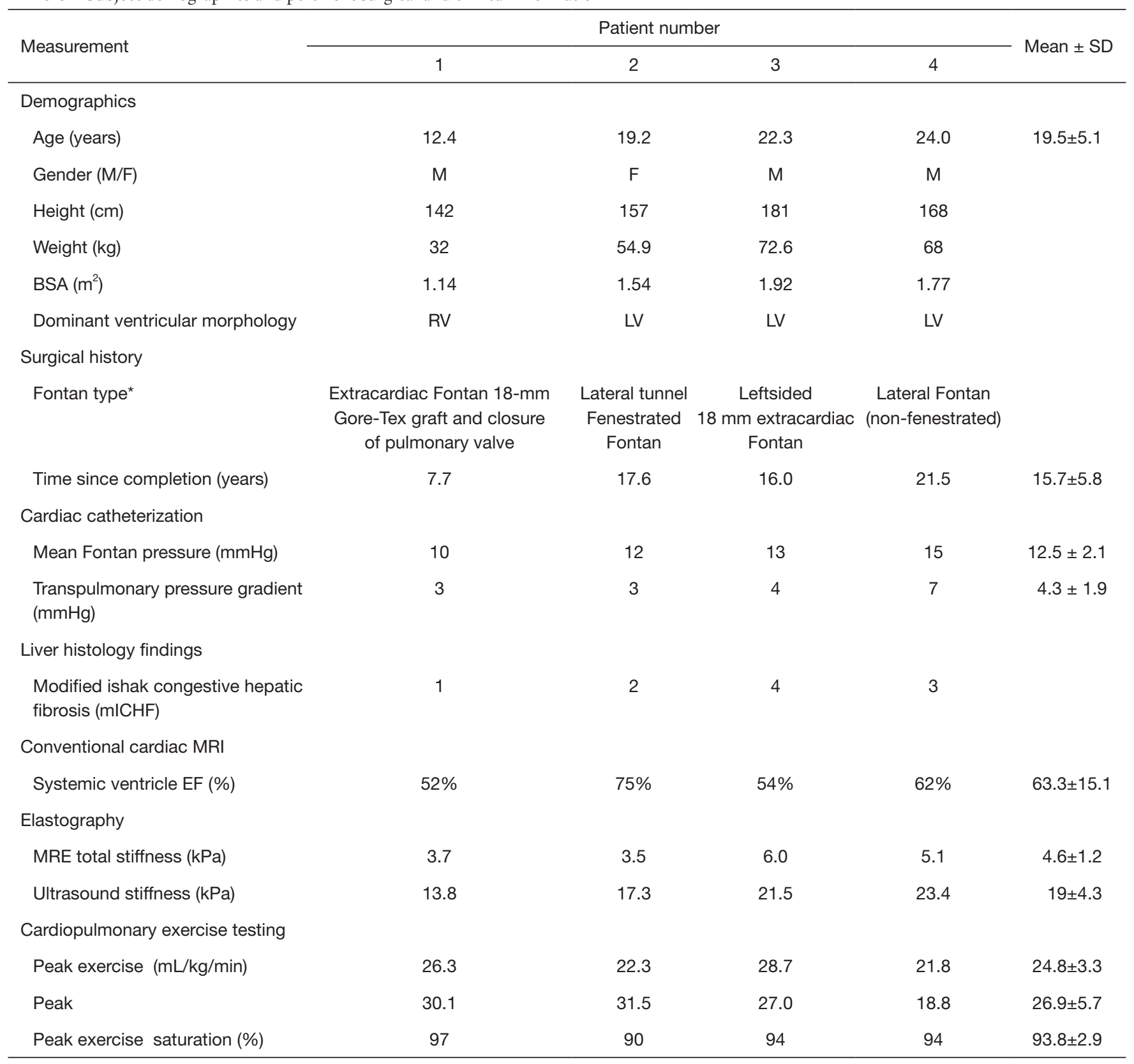

\section{Results}

\section{Patient demographics and clinical findings}

A summary of clinical evaluation is presented in Table 2 . Extensive information can be found in Table S1. Despite heterogeneity in clinical history, all patients demonstrated relatively high cardiovascular function with peak oxygen consumption $\mathrm{V}_{2}$ above $20 \mathrm{~mL} / \mathrm{kg} / \mathrm{min}$, robust increases in heart rate and systolic blood pressure during exercise test, and peak ventilatory efficiency $\dot{\mathrm{V}} \mathrm{E} / \mathrm{VCO}_{2}$ below levels associated with heart failure. Conventional MRI showed systemic ventricles with ejection fractions between $52 \%$ and $75 \%$.

\section{Exercise cardiac MRI}

Changes in stroke volume, heart rate, and cardiac output 
Table 3 Changes in stroke index, heart rate, and cardiac index during exercise MRI study

\begin{tabular}{lccccc}
\hline \multirow{2}{*}{ Measurement } & \multicolumn{5}{c}{ Patient number } \\
\cline { 2 - 5 } & 1 & 2 & 3 & 4 & Mean \pm SD \\
\hline $\begin{array}{l}\text { Stroke index } \\
\left.\text { (mL/beat } \mathrm{m}^{2}\right)\end{array}$ & & & & & \\
Resting & 76.0 & 59.6 & 38.9 & 41 & $53.9 \pm 17.4$ \\
Peak exercise & 126.4 & 75.8 & 102.1 & 100 & $101.1 \pm 20.7$ \\
Absolute increase & 50.5 & 16.2 & 63.2 & 59 & $47.2 \pm 21.3$ \\
Percent increase & $66 \%$ & $27 \%$ & $162 \%$ & $144 \%$ & $100 \pm 64$ \\
Heart rate (bpm) & & & & & \\
Resting & & 58 & 59 & 49 & $55.3 \pm 5.5$ \\
Peak exercise & & 88 & 78 & 72 & $79.3 \pm 8.1$ \\
Absolute increase & & 30 & 19 & 23 & $24.0 \pm 5.6$ \\
Percent increase & & $52 \%$ & $32 \%$ & $47 \%$ & $44 \pm 10$ \\
Cardiac index & & & & & \\
(mL/min m ${ }^{2}$ ) & & & & & \\
Resting & & 3.5 & 2.3 & 2 & $2.6 \pm 0.8$ \\
Peak exercise & 6.7 & 7.9 & 7.2 & $7.2 \pm 0.6$ \\
Absolute increase & & 3.2 & 5.6 & 5.2 & $4.7 \pm 1.3$ \\
Percent increase & & $93 \%$ & $242 \%$ & $259 \%$ & $198 \pm 91$ \\
\hline
\end{tabular}

Heart rate during exercise was unavailable for Patient 1 limiting results to only changes in stroke index.

from rest to exercise are shown in Table 3. Overall, stroke index, heart rate, and cardiac output significantly $(\mathrm{P}=0.02)$ increased. The change in heart rate corresponded to an increase, as a percentage of predicted maximum, from $30 \% \pm 3 \%$ (range, $26-31 \%$ ) to $42 \% \pm 5 \%$ (range, $38-47 \%$ ).

\section{Association of changes in function during exercise with clinical bistory}

There was a higher increase in stroke index in patients 3 and 4, compared to Patients 1 and 2 despite patients 3 and 4 being older, having longer Fontan duration, higher mean Fontan pressures, and worse liver findings on histology and elastography.

Only one patient had a systemic right ventricle (patient 1) who happened to be the youngest subject, with the lowest Fontan pressure and the lowest Fibrosis score. However, despite these favorable parameters, this subject had a limited increase in stroke index with exercise. Unfortunately, heart rate at peak exercise was not recorded which prohibited estimation of cardiac index changes.

\section{Association of changes in function during exercise as a function of liver findings}

Figure 1 illustrates the changes in stroke index observed during exercise MRI as a function of mICHF score. Amongst the systemic left ventricle patients (patients 2-4), patient 2 had the highest stroke index at rest but the lowest stroke volume at maximum exercise. As seen in Table 3, this led to the lowest measured increase with exercise. However, patient 2 had a higher resting heart rate and achieved the highest exercise heart rate. This led to the highest resting cardiac index but the lowest exercise cardiac index. Similarly, patients 3 and 4 had lower resting cardiac index but achieved higher exercise cardiac index driven primarily by increases in stroke index. These findings appear associated with mICHF score. In our cohort, patients with lower mICHF score (score $=1$ or 2 ) demonstrated lower changes in stroke index than patients with higher mICHF scores.

\section{Associations between flow modeling and clinical findings}

Patients 3 and 4 were unable to undergo computational flow modeling due to the right pulmonary artery being truncated in the MR angiogram imaging which precluded accurate anatomical delineation. Figure 2 illustrates the results from flow modeling in patients 1 and 2. Specifically, we observed absolute and spatial differences in velocity, shear stress, and oscillatory shear index in two patients with different Fontan types and different systemic ventricles. Patient 1 demonstrated more laminar flow, less shear stress, and less asymmetry than patient 2 .

Despite similar Fontan pressures, transpulmonary pressure gradient, and cardiac output on flow MRI, the percentage of inferior vena cava flow to the right lung was markedly higher in patient $2(73 \%)$ than patient $1(39 \%)$ due to the relative position of the Fontan pathway and the relative resistance in the right and left pulmonary arteries. This can be seen in the higher flow profiles observed for patient 2 in Figure 2 (top right).

Combining the differences in flow distribution with vessel geometry led to increased calculated shear stress in the right pulmonary artery of patient 2 compared to patient 1 (Figure 2 middle). However, the highest oscillatory shear index values (Figure 2 bottom) were observed in the Fontan 

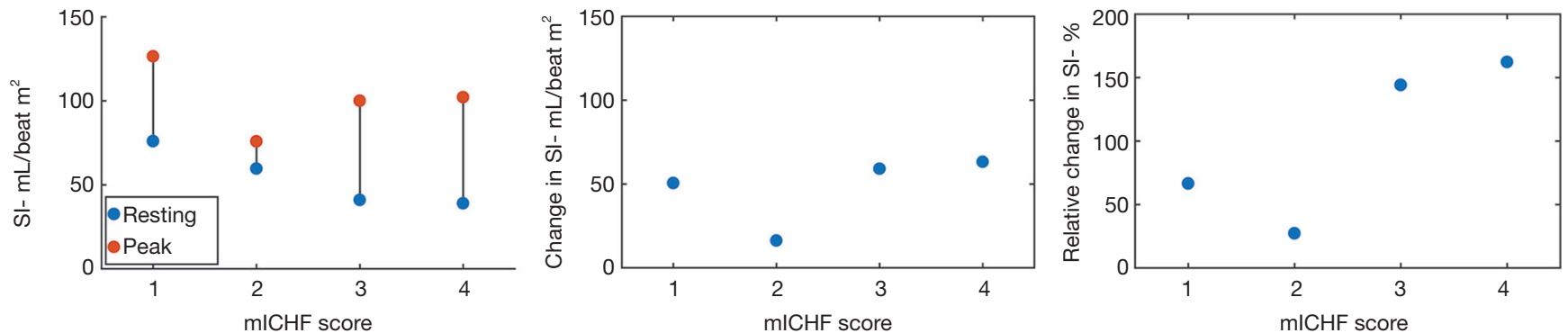

Figure 1 Stroke index $\left(\mathrm{mL} /\right.$ beat $\left.\mathrm{m}^{2}\right)$ measured via MRI at rest and during exercise as well as absolute and percent changes as a function of Fontan-specific mICHF score. The mICHF score for each patient were as follows: Patient 1 Score = 1, Patient 2 Score = 2, Patient 3 Score $=4$, Patient 4 Score $=3$. mICHF, Modified Ishak Congestive Hepatic Fibrosis.

Patient 1-Extracardiac Fontan
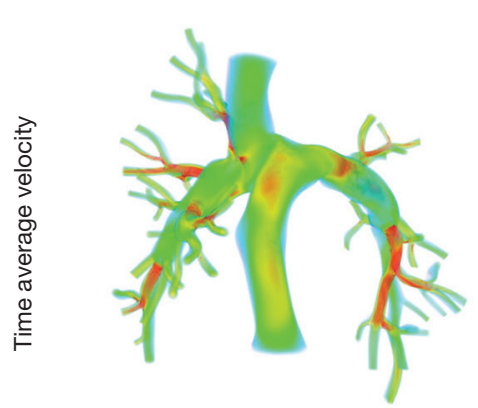
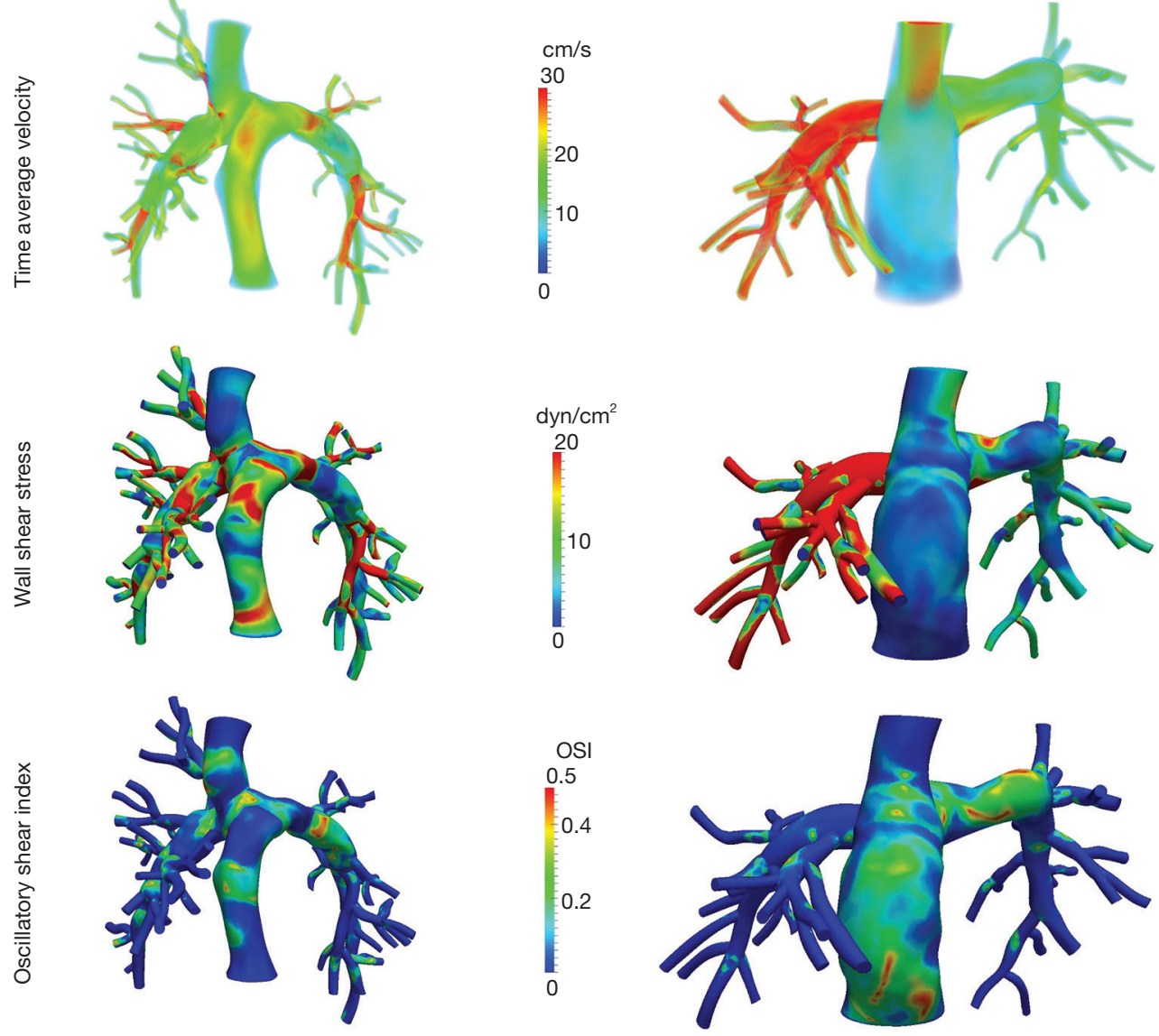

Figure 2 3D visualization of time averaged velocity, wall shear stress, and oscillatory shear index in Fontan conduit and pulmonary vasculature calculated from computation fluid dynamics utilizing MRI phase contrast flow measurement for patients 1 and 2 at rest. Patient 1 has a more even distribution of flow and wall shear stress whereas Patient 2 has high blood flow velocity and shear stress in the right pulmonary artery. Patient 1 is 12.4 years old with an extra-cardiac Fontan, systemic RV, low Fontan pressure (10 mmHg), and low transpulmonary gradient $(3 \mathrm{mmHg}$ ), and has low Fibrosis measures (mICHF of $1, \mathrm{MRE}$ of $3.7 \mathrm{kPa})$. Subject 2 is 19.2 years old with a lateral tunnel Fontan, low Fontan pressure $(12 \mathrm{mmHg})$, low transpulmonary gradient ( $3 \mathrm{mmHg}$ ), Fibrosis scores of $\mathrm{mICHF}=2 \mathrm{and} \mathrm{MRE}$ of $3.5 \mathrm{kPa}$. mICHF, Modified Ishak Congestive Hepatic Fibrosis; MRE, magnetic resonance elastography; OSI, oscillatory shear index. 
conduit itself (as opposed to occurring in the pulmonary arteries).

While Patient 1 had the lowest Fontan pressure and least liver fibrosis by biopsy and elastography in our cohort, it is difficult to make any inferences since this patient was younger than patient 2 (12.4 vs. 19.2 years old) and had a different systemic ventricle and Fontan type than patient 1.

\section{Flow modeling and changes with exercise}

Amongst the two patients with computational flow modeling, we observed differences during exercise. Specifically, patient 2 had lower stroke index than patient 1 at rest and during exercise. This led to a lower increase in absolute stroke index.

\section{Discussion}

In this study, we obtained exercise MRI information in a small cohort of Fontan patients with high cardiovascular function based on clinical measures. We also obtained computational flow models in two subjects. Despite the small size and relatively high baseline cardiovascular function for Fontan physiology of our cohort, we observed marked differences in both hemodynamic changes with exercise and flow modeling emphasizing the importance of deep phenotyping.

Our cohort had fairly high baseline function according to clinical examination. Furthermore, liver evaluation did not reveal clear signs of cirrhosis or extensive fibrosis. Despite this fairly homogenous phenotype of high baseline cardiovascular function and limited liver impairment, we observed marked differences in response to exercise and flow patterns at rest that are not well described by conventional clinical parameters. For example, prior studies suggest that being older and having a longer time since Fontan completion leads to worse liver findings and exercise capability $(5,12)$. While we observed this trend in our liver parameters (histological and elastography), clinical exercise testing showed similar peak oxygen consumption values in the older patients despite having a higher peak systolic blood pressure. In addition, our exercise MRI protocol revealed larger increases in stroke index and cardiac index in the two older patients (patients 3 and 4) driven primarily by lower resting stroke index. While higher baseline physical activity is typically associated with a higher resting stroke index (and lower resting heart rate), it is possible that in our cohort, the younger patients had higher stroke index associated with higher inotropic state (with less contractile reserve).

Furthermore, hepatic complications after Fontan are known to be multifactorial without an exact known mechanism (25). Passive congestion and periods of hypoxia due to low cardiac output may drive inflammation or repetitive mechanical stretch/compression (25). These complications could then increase systemic vascular resistance, thereby leading to low cardiac index. In our cohort, we observed a higher increase in stroke index in patients with higher liver fibrosis. However, these patients had lower resting stroke index. As a result, it remains unclear whether these observations are linked physiologically. While a low resting stroke index may enable a larger increase with exercise (assuming a similar peak stroke index) in some patients, in others, it may indicate a failing Fontan, low output state. Differentiating these two responses is facilitated by deep phenotyping.

The exercise MRI protocol entailed a stepping motion while in a supine position. Patients achieved peak exercise heart rates of $42 \% \pm 5 \%(38-47 \%)$ of their predicted max. This was lower than the values observed during clinical CPET $(78.0 \% \pm 8.1 \%)$. This difference is expected given both the sub-maximal exercise goal (20 W resistance) as well as the supine posture associated with the MRIimaging set-up $(26,27)$. Whether differences we observed in response to sub-maximal exercise are seen during maximal exercise should be evaluated in a larger cohort.

This study presents flow modeling observations alongside clinical measures of hemodynamics, liver fibrosis, and exercise capacity which is new. Specifically, although Patients 1 and Patient 2 both had low Fontan pressures, low transpulmonary gradient, low mICHF score and low MR elastography, they exhibited stark differences in terms of flow distribution and shear stress (Figure 2). Previously, the absence of hepatic venous return has been associated with development of pulmonary arteriovenous malformations (28) and areas low shear stress have been associated with subsequent thrombosis in patients with Y-graft modification of the Fontan procedure (24). Our results suggest patient 2's flow imbalance could increase the risk of pulmonary arteriovenous malformations and low shear stress in the Fontan conduit and left pulmonary artery could increase the risk of thrombosis. While these differences could provide valuable information-different from clinical hemodynamic and liver findings, the clinical role of these personalized assessments remains unclear. Our future objectives are to encourage routine screening 
of Fontan patients in organized single ventricle multidisciplinary clinics, evaluating not only their cardiac issues but also their end organs. We are hoping that with this methodical and personalized surveillance that we would be able to abort the need to be reactive when those patients endure fatal complications from the natural course of their disease.

A limitation of this observational series is the small number of patients. However, even in this small and fairly homogeneous cohort of patients with clinically measured high cardiovascular function, we observed significant variations, potentially denoting different adaptation mechanisms. Further mechanistic explanations of these observed differences are left to future studies.

While it remains unclear what constellation of findings on clinical evaluation, exercise MRI, and computational modeling impact patient outcomes, we demonstrate differences in our exercise MRI and computational modeling data that may provide mechanistic insight into patient-specific adaptive mechanisms.

\section{Acknowledgments}

Funding: Contijoch F is supported by NIH HL143113.

\section{Footnote}

Provenance and Peer Review: This article was commissioned by the Guest Editor (Raghav A. Murthy) for the series "Management of Congenital Heart Disease" published in Fournal of Thoracic Disease. The article was sent for external peer review organized by the Guest Editor and the editorial office.

Conflicts of Interest: The series "Management of Congenital Heart Disease" was commissioned by the editorial office without any funding or sponsorship. The authors have no other conflicts of interest to declare.

Ethical Statement: The authors are accountable for all aspects of the work in ensuring that questions related to the accuracy or integrity of any part of the work are appropriately investigated and resolved.

Open Access Statement: This is an Open Access article distributed in accordance with the Creative Commons Attribution-NonCommercial-NoDerivs 4.0 International License (CC BY-NC-ND 4.0), which permits the non- commercial replication and distribution of the article with the strict proviso that no changes or edits are made and the original work is properly cited (including links to both the formal publication through the relevant DOI and the license). See: https://creativecommons.org/licenses/by-nc-nd/4.0/.

\section{References}

1. Gewillig M, Goldberg DJ. Failure of the Fontan Circulation. Heart Fail Clin 2014;10:105-16.

2. Takahashi K, Inage A, Rebeyka IM, et al. Real-time 3-dimensional echocardiography provides new insight into mechanisms of tricuspid valve regurgitation in patients with hypoplastic left heart syndrome. Circulation 2009;120:1091-8.

3. Kanzaki T, Yamagishi M, Miyazaki T, et al. Valve-Sparing Neoaortic Root Replacement Late After the Norwood and Fontan Procedures. Ann Thorac Surg 2015;99:309-12.

4. Fontan F, Baudet E. Surgical repair of tricuspid atresia. Thorax 1971;26:240-8.

5. Diller GP, Dimopoulos K, Okonko D, et al. Exercise intolerance in adult congenital heart disease: Comparative severity, correlates, and prognostic implication. Circulation 2005;112:828-35.

6. Giardini A, Hager A, Napoleone CP, et al. Natural History of Exercise Capacity After the Fontan Operation: A Longitudinal Study. Ann Thorac Surg 2008;85:818-21.

7. Heinemann M, Breuer J, Steger V, et al. Incidence and Impact of Systemic Venous Collateral Development after Glenn and Fontan Procedures*. Thorac Cardiovasc Surg 2001;49:172-8.

8. Algaze CA, Koth AM, Faberowski LW, et al. Acute Kidney Injury in Patients Undergoing the Extracardiac Fontan Operation With and Without the Use of Cardiopulmonary Bypass. Pediatr Crit Care Med 2017;18:34-43.

9. Lee D, Levin A, Kiess M, et al. Chronic kidney damage in the adult Fontan population. Int J Cardiol 2018;257:62-6.

10. Lemmer JH, Coran AG, Behrendt DM, et al. Liver fibrosis (cardiac cirrhosis) five years after modified Fontan operation for tricuspid atresia. J Thorac Cardiovasc Surg 1983;86:757-60.

11. Schwartz MC, Sullivan LM, Glatz AC, et al. Portal and Sinusoidal Fibrosis are Common on Liver Biopsy After Fontan Surgery. Pediatr Cardiol 2013;34:135-42.

12. Rychik J, Veldtman G, Rand E, et al. The precarious state of the liver after a fontan operation: Summary of a multidisciplinary symposium. Pediatr Cardiol 2012;33:1001-12. 
13. Rychik J, Atz AM, Celermajer DS, et al. Evaluation and Management of the Child and Adult With Fontan Circulation: A Scientific Statement From the American Heart Association. Circulation 2019. [Epub ahead of print].

14. Huwart L, Sempoux C, Vicaut E, et al. Magnetic Resonance Elastography for the Noninvasive Staging of Liver Fibrosis. Gastroenterology 2008;135:32-40.

15. Millonig G, Friedrich S, Adolf S, et al. Liver stiffness is directly influenced by central venous pressure. J Hepatol 2010;52:206-10.

16. Venkatesh SK, Yin M, Ehman RL. Magnetic Resonance Elastography of Liver. J Comput Assist Tomogr 2013;37:887-96.

17. Silva-Sepulveda JA, Fonseca Y, Vodkin I, et al. Evaluation of Fontan liver disease: Correlation of transjugular liver biopsy with magnetic resonance and hemodynamics. Congenit Heart Dis 2019;14:600-8.

18. Schmidt JP, Delp SL, Sherman MA, et al. The Simbios National Center: Systems Biology in Motion. Proc IEEE Inst Electr Electron Eng 2008;96:1266-80.

19. Updegrove A, Wilson NM, Merkow J, et al. SimVascular: An Open Source Pipeline for Cardiovascular Simulation. Ann Biomed Eng 2017;45:525-41.

20. Lan H, Updegrove A, Wilson NM, et al. A Re-Engineered Software Interface and Workflow for the Open-Source SimVascular Cardiovascular Modeling Package. J Biomech Eng 2018;140:024501.

21. Marsden AL, Bernstein AJ, Reddy VM, et al. Evaluation of a novel Y-shaped extracardiac Fontan baffle using

Cite this article as: Contijoch F, Li B, Yang W, Silva-Sepulveda JA, Vodkin I, Printz B, Vavinskaya V, Hegde S, Marsden A, El-Sabrout H, Alshawabkeh L, Moore JW, El-Said H. Exercise MRI highlights heterogeneity in cardiovascular mechanics among patients with Fontan circulation: proposed protocol for routine evaluation. J Thorac Dis 2020;12(3):1204-1212. doi: $10.21037 /$ jtd.2019.09.59 computational fluid dynamics. J Thorac Cardiovasc Surg 2009;137:394-403.e2.

22. Yang W, Vignon-Clementel IE, Troianowski G, et al. Hepatic blood flow distribution and performance in conventional and novel Y-graft Fontan geometries: A case series computational fluid dynamics study. J Thorac Cardiovasc Surg 2012;143:1086-97.

23. Troianowski G, Taylor CA, Feinstein JA, et al. Threedimensional simulations in Glenn patients: clinically based boundary conditions, hemodynamic results and sensitivity to input data. J Biomech Eng 2011;133:111006.

24. Yang W, Chan FP, Reddy VM, et al. Flow simulations and validation for the first cohort of patients undergoing the Y-graft Fontan procedure. J Thorac Cardiovasc Surg 2015;149:247-55.

25. Asrani SK, Asrani NS, Freese DK, et al. Congenital heart disease and the liver. Hepatology 2012;56:1160-9.

26. Proctor DN, Sinning WE, Bredle DL, et al. Cardiovascular and peak VO2 responses to supine exercise: effects of age and training status. Med Sci Sports Exerc 1996;28:892-9.

27. Leyk D, Eßfeld D, Hoffmann U, et al. Postural effect on cardiac output, oxygen uptake and lactate during cycle exercise of varying intensity. Eur J Appl Physiol Occup Physiol 1994;68:30-5.

28. Pike NA, Vricella LA, Feinstein JA, et al. Regression of severe pulmonary arteriovenous malformations after Fontan revision and "hepatic factor" rerouting. Ann Thorac Surg 2004;78:697-9. 
Table S1 Subject demographics and pertinent surgical and clinical information

\begin{tabular}{|c|c|c|c|c|c|}
\hline \multirow{2}{*}{ Measurement } & \multicolumn{4}{|c|}{ Patient number } & \multirow{2}{*}{ Mean \pm SD } \\
\hline & 1 & 2 & 3 & 4 & \\
\hline \multicolumn{6}{|l|}{ Demographics } \\
\hline Age (years) & 12.4 & 19.2 & 22.3 & 24.0 & $19.5 \pm 5.1$ \\
\hline Gender (M/F) & M & $\mathrm{F}$ & M & M & \\
\hline Height (cm) & 142 & 157 & 181 & 168 & \\
\hline Weight (kg) & 32 & 55 & 73 & 68 & \\
\hline $\mathrm{BSA}\left(\mathrm{m}^{2}\right)$ & 1.14 & 1.54 & 1.92 & 1.77 & \\
\hline $\begin{array}{l}\text { Dominant ventricular } \\
\text { morphology }\end{array}$ & $\mathrm{RV}$ & LV & LV & LV & \\
\hline Diagnosis & $\begin{array}{l}\text { Heterotaxy and asplenia. Mildly } \\
\text { unbalanced AV canal defect, DORV, } \\
\text { D-malposed great vessels, sub-valve } \\
\text { pulmonary stenosis, right aortic arch, } \\
\text { and partial anomalous venous return } \\
\text { to superior vena cava }\end{array}$ & $\begin{array}{l}\text { Tricuspid atresia, } \\
\text { normally related great } \\
\text { vessels with a restrictive } \\
\text { ventricular septal defect }\end{array}$ & $\begin{array}{l}\text { Isolated dextrocardia, } \\
\text { complete AV canal, } \\
\text { pulmonary atresia, } \\
\text { interrupted IVC, } \\
\text { hypoplastic right ventricle }\end{array}$ & $\begin{array}{l}\text { Pulmonary } \\
\text { atresia with intact } \\
\text { ventricular septum, } \\
\text { RCA fistula }\end{array}$ & \\
\hline \multicolumn{6}{|l|}{ Surgical history } \\
\hline Procedural history & $\begin{array}{l}\text { Repair of partial anomalous } \\
\text { pulmonary venous return, pulmonary } \\
\text { artery band, bidirectional Glenn, }\end{array}$ & $\begin{array}{l}\text { Pulmonary artery band } \\
\text { and atrial septectomy, } \\
\text { bidirectional Glenn }\end{array}$ & $\begin{array}{l}\text { Right modified BT shunt, } \\
\text { Bidirectional Glenn }\end{array}$ & $\begin{array}{l}\text { Right modified } \\
\text { BT shunt, Hemi- } \\
\text { Fontan, tricuspid } \\
\text { valve oversewn }\end{array}$ & \\
\hline Fontan type* & $\begin{array}{l}\text { Extracardiac Fontan 18- mm } \\
\text { Gore-Tex graft and closure of } \\
\text { pulmonary valve (non-fenestrated) }\end{array}$ & $\begin{array}{l}\text { Lateral tunnel } \\
\text { Fenestrated Fontan }\end{array}$ & $\begin{array}{l}\text { Left sided } 18 \mathrm{~mm} \\
\text { extracardiac Fontan } \\
\text { (non-fenestrated) }\end{array}$ & $\begin{array}{l}\text { Lateral Fontan } \\
\text { (non-fenestrated) }\end{array}$ & \\
\hline Open fenestration at time of MRI & No & No & No & No & \\
\hline Time since completion (years) & 7.7 & 17.6 & 16.0 & 21.5 & $15.7 \pm 5.8$ \\
\hline \multicolumn{6}{|l|}{ Cardiac catheterization } \\
\hline Mean Fontan pressure $(\mathrm{mmHg})$ & 10 & 12 & 13 & 15 & $12.5 \pm 2.1$ \\
\hline Transpulmonary pressure & 3 & 3 & 4 & 7 & $4.3 \pm 1.9$ \\
\hline \multicolumn{6}{|l|}{ Gradient $(\mathrm{mmHg})$} \\
\hline \multicolumn{6}{|l|}{ Histological findings } \\
\hline Ishak portal fibrosis & 0 & 1 & 4 & 1 & Ishak portal fibrosis \\
\hline Modified Scheuer fibrosis & 0 & 1 & 3 & 1 & $\begin{array}{l}\text { Modified Scheuer } \\
\text { fibrosis }\end{array}$ \\
\hline Sinusoidal fibrosis & 2 & 2 & 2 & 3 & Sinusoidal fibrosis \\
\hline Congestive hepatic fibrosis & 1 & $2 \mathrm{~A}$ & 3 & 3 & $\begin{array}{l}\text { Congestive hepatic } \\
\text { fibrosis }\end{array}$ \\
\hline $\begin{array}{l}\text { Modified Ishak congestive } \\
\text { hepatic fibrosis (mICHF) }\end{array}$ & 1 & 2 & 4 & 3 & $\begin{array}{l}\text { Modified Ishak } \\
\text { congestive hepatic } \\
\text { fibrosis (mICHF) }\end{array}$ \\
\hline \multicolumn{6}{|l|}{ Conventional cardiac MRI } \\
\hline Systemic ventricle EF (\%) & $52 \%$ & $75 \%$ & $54 \%$ & $62 \%$ & $63.3 \pm 15.1$ \\
\hline \multicolumn{6}{|l|}{ Elastography } \\
\hline MRE total stiffness $(\mathrm{kPa})$ & 3.7 & 3.5 & 6.0 & 5.1 & $4.6 \pm 1.2$ \\
\hline Ultrasound stiffness $(\mathrm{kPa})$ & 13.8 & 17.3 & 21.5 & 23.4 & $19 \pm 4.3$ \\
\hline Ultrasound IQR/median ratio & 7 & 16 & 19 & 25 & $16.8 \pm 7.5$ \\
\hline \multicolumn{6}{|l|}{ Cardiopulmonary exercise testing } \\
\hline Peak exercise $\dot{\mathrm{V}}_{2}(\mathrm{~mL} / \mathrm{kg} / \mathrm{min})$ & 26.3 & 22.3 & 28.7 & 21.8 & $24.8 \pm 3.3$ \\
\hline Peak $\dot{\mathrm{V}} \mathrm{O}_{2}$ as $\%$ of max pred (\%) & $49 \%$ & $54 \%$ & $60 \%$ & $46 \%$ & $52.3 \pm 6.1$ \\
\hline Peak heart rate (HR) (bpm) & 176 & 136 & 137 & 142 & $147.8 \pm 19$ \\
\hline Peak HR as $\%$ of max pred (\%) & $90 \%$ & $73 \%$ & $73 \%$ & $76 \%$ & $77.8 \pm 8.1$ \\
\hline $\begin{array}{l}\text { Peak systolic blood pressure } \\
\text { (SBP) (mmHg) }\end{array}$ & 132 & 154 & 170 & 174 & $157.5 \pm 19.1$ \\
\hline Peak SBP as \% of max pred (\%) & $91 \%$ & $95 \%$ & $87 \%$ & $96 \%$ & $92.3 \pm 4.1$ \\
\hline Peak VE/Vं $\mathrm{CO}_{2}$ & 30.1 & 31.5 & 27.0 & 18.8 & $26.9 \pm 5.7$ \\
\hline Baseline $\mathrm{O}_{2}$ saturation (\%) & $98 \%$ & $93 \%$ & $96 \%$ & $95 \%$ & $95.5 \pm 2.1$ \\
\hline Peak exercise $\mathrm{O}_{2}$ saturation (\%) & $97 \%$ & $90 \%$ & $94 \%$ & $94 \%$ & $93.8 \pm 2.9$ \\
\hline \multicolumn{6}{|l|}{ Laboratory testing } \\
\hline APRI & 0.05 & 0.07 & 0.08 & 0.14 & $0.08 \pm 0.04$ \\
\hline FIB-4 & 0.43 & 0.44 & 1.58 & 1.68 & $1.03 \pm 0.69$ \\
\hline
\end{tabular}

$\mathrm{BSA}$, body surface area; V-V, venous-venous; $\mathrm{EF}$, ejection fraction; IQR, interquartile ratio; $\mathrm{V}_{2}$ : oxygen consumption; VE, minute ventilation; $\dot{\mathrm{V}}_{2}$, carbon dioxide production; $\mathrm{VE} / \dot{\mathrm{V}} \mathrm{CO}_{2}$, ventilatory efficiency; APRI, AST-to-Platelet Ratio Index; FIB-4, Fibrosis-4. 